\title{
Note on Fieldwork, Names, Transliteration, and Currency
}

My research subjects include primarily Yunnanese Chinese migrants (hereafter Yunnanese migrants) who are residing in Burma (or Myanmar) and secondarily those who have moved from Burma to another country, especially Thailand. The population is composed of both Han Chinese and Muslims. On account of their continuous mobility (in terms of both internal and external migrations), I often use "migrant Yunnanese" in this book. Sometimes I also specify "Yunnanese in Burma," "Yunnanese in Thailand," and so on, depending on the context. Throughout history the Yunnanese have basically undertaken migration from Yunnan in southwestern China to upland Southeast Asia by land; the Yunnanese migrants in the region are thus also referred to as "overland Yunnanese" (Chang 2006; Forbes 1987, 1-2; Hill 1983; Sun 2000, 10). The term is in contrast to "overseas/maritime Chinese." The latter are derived from the coastal provinces of southeastern China, primarily the Hokkien/Fujianese, the Cantonese, and the Hakka, who set off for host countries by sea.

I started my anthropological research among the Yunnanese migrants in northern Thailand in late 1994. According to the Yunnanese Association 
in Chiang Mai, the estimates of the total population of Yunnanese migrants in Thailand are between 100,000 and 150,000. Most of them are located along the borders of Chiang Rai, Chiang Mai, and Mae Hongson Provinces. Many in the younger generation have relocated to Chiang Mai and Bangkok. In 2000, I extended my fieldwork to Burma (now Myanmar), where a much larger Yunnanese population resides. No accurate population figure is available there, either, but estimates given by informants range from half a million to one million. ${ }^{1}$ These estimates also include the Kokang Yunnanese, largely residing in Shan State. My field sites in Burma cover major cities, towns, and villages where Yunnanese migrants are concentrated, primarily in upper Burma. Because of practical constraints, I have however not been able to travel as widely as I wished for field research in the country. Apart from Thailand and Burma, I have also conducted research among Yunnanese who have migrated to Taiwan from Thailand and Burma and returnees to China (many of them investors in Yunnan, Guangzhou, and Hong Kong). The primary field data in this book are collected up to 2010, but later developments in Burma have also been integrated. ${ }^{2}$ For data collecting I sometimes took notes, while at other times I used a tape recorder or, in later days, an MP3 recorder, depending on the situation.

Yunnanese in Burma and Thailand normally address each other with affiliated terms based on the kinship principle. Terms such as "Mr." and "Mrs." are used formally for people with some social status. Learning to address people correctly was the first step in my fieldwork. In this book, I refer to the narrators in the way I addressed them in the field. However, out of respect to teachers in Chinese society, most of my informants address me as "Teacher Chang."

All the informants' names given in this book are pseudonyms. Sometimes I have had to change the narrators' residential locations or professions in order to disguise their identification. Interview dates are indicated only when they will not compromise the interviewees' safety. I use the pinyin Romanization for transliteration of Chinese characters.

1. The estimate of the total population of the ethnic Chinese in Burma (including both overland Yunnanese and maritime Chinese) given by the CIA is about 1.65 million, accounting for 3 percent of the whole nation's population; see https:/www.cia.gov/library/publications/theworld-factbook/geos/bm.html (last access date October 2, 2013).

2. The accumulated time on fieldwork from 1994 to 2010 is thirty-six months. 
There are no standard transliterations for names of places in Burma. Some places changed names after 1988. I use new names in this book but add old names in brackets when they appear the first time. Some places share the same name, or the same place has different names. For example, "Panglong" is the name for the famous Shan town where the "Panglong Agreement" was signed in 1947. It is also the name for an important place that Yunnanese Muslims resettled after fleeing from Yunnan in the wake of the Muslim Rebellion (1856-1873 CE). As the first "Panglong" is also called "Pinlong," I use the latter name in order to distinguish it from the Yunnanese Muslims' "Panglong."

Kyat is Burmese currency. Its exchange rate with US dollars is 780 kyat to one dollar in June 2011. (It was around 1,000 kyat to one dollar two years earlier.) Baht is Thai currency. Its exchange rate with US dollars is 30.4 baht to one dollar in June 2011. NT (new Taiwan dollar) is the Taiwanese currency. Its exchange rate with US dollars is $28.7 \mathrm{NT}$ to one dollar in June 2011. RMB (renminbi) is Chinese currency. Its exchange rate with US dollars is 6.39 RMB to one dollar in August 2011. 


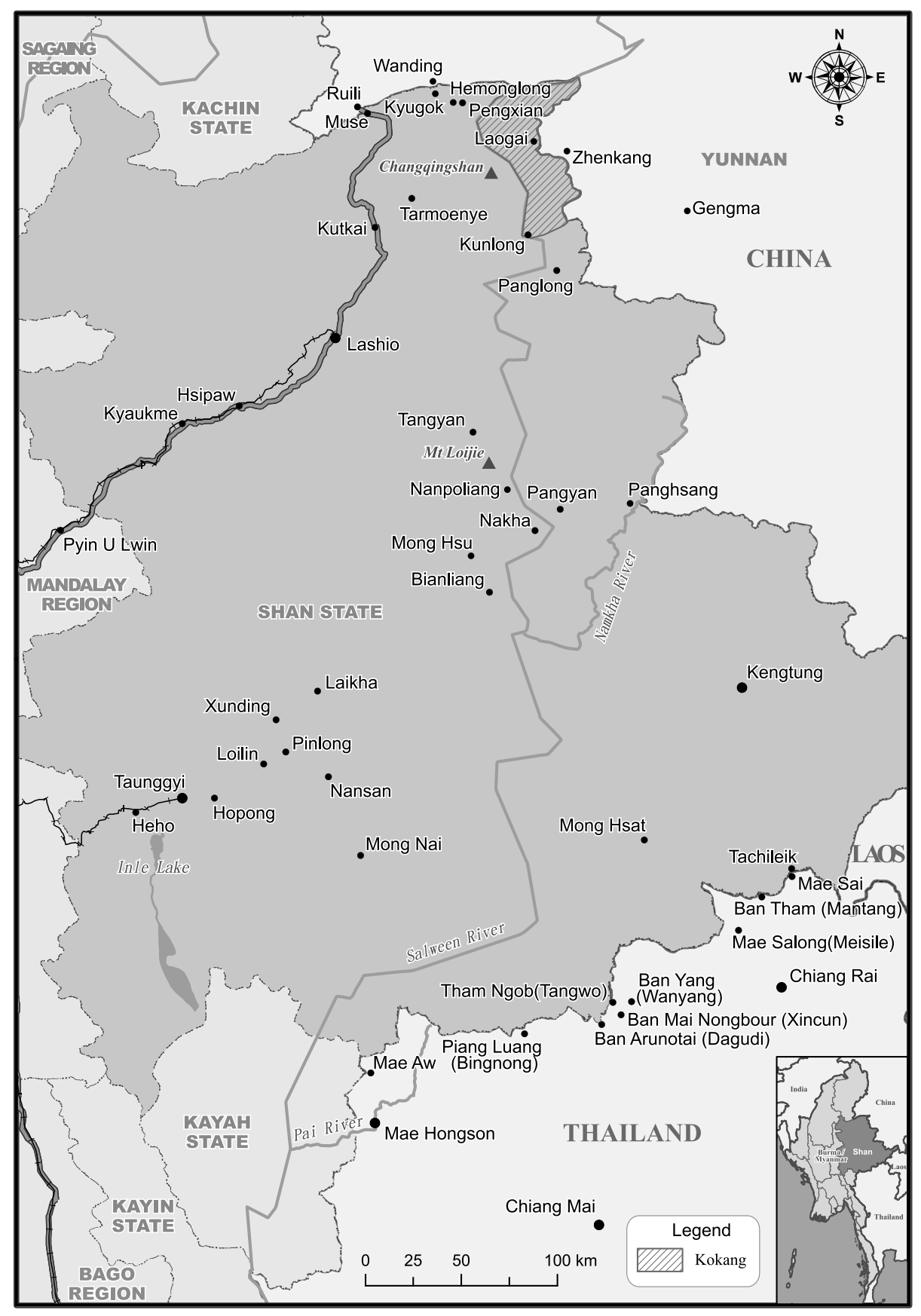

Map 1. Shan State of Burma and northern Thailand 


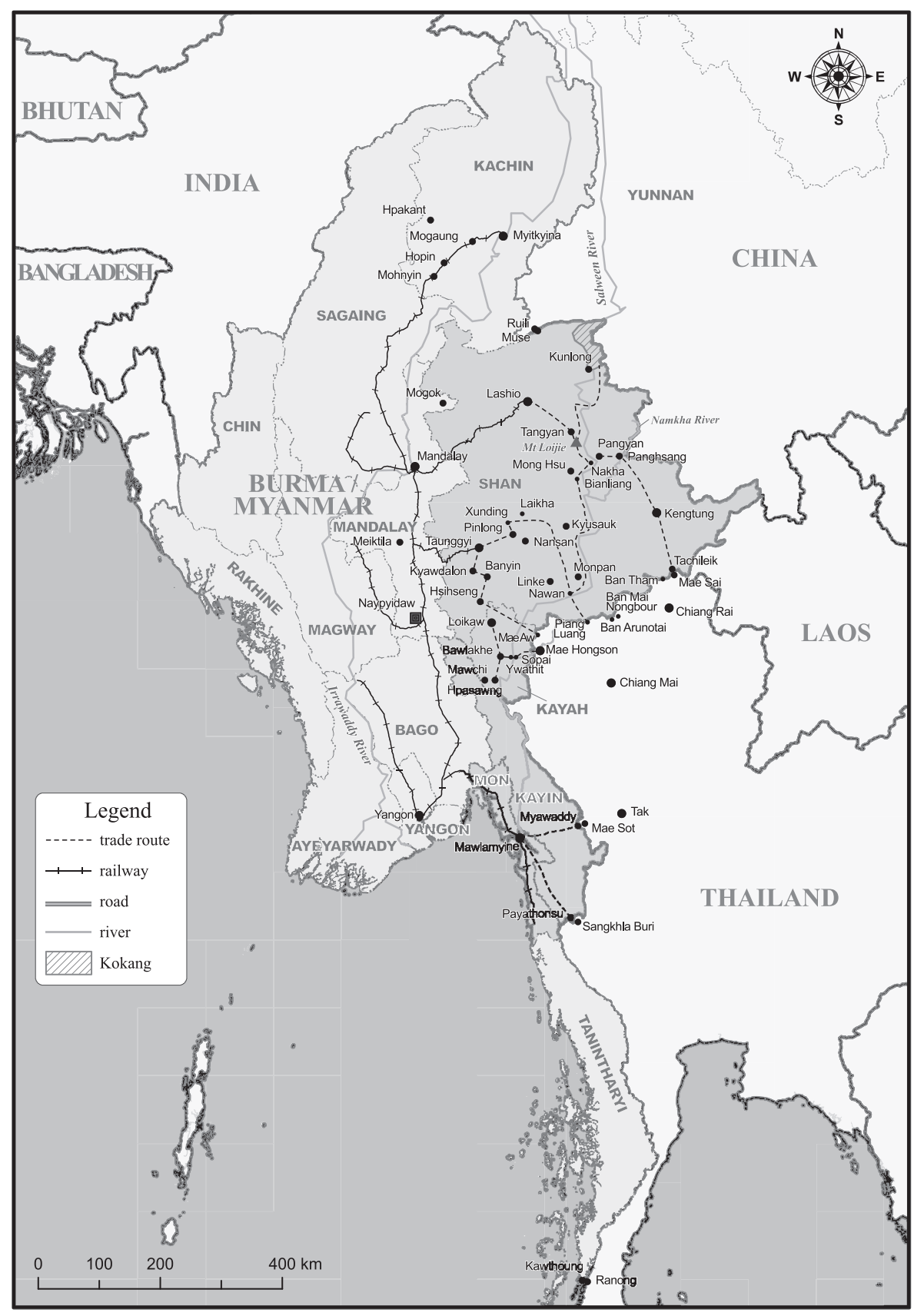

Map 2. Major underground trading routes between Burma and Thailand 


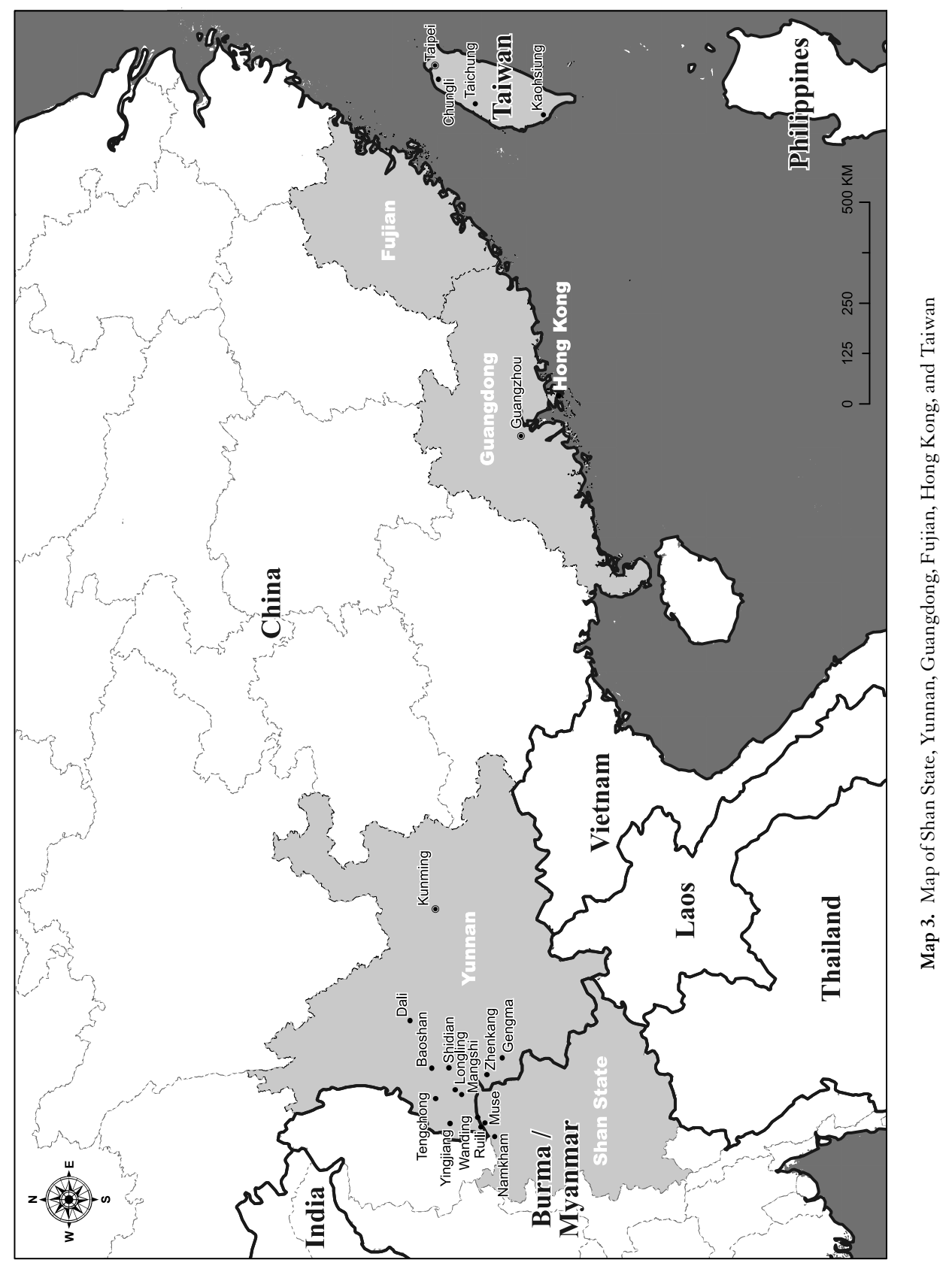

